\title{
Embryonic Stem Cells and Nuclear Transfer Strategies
}

\author{
Present State and Future Prospects ${ }^{1}$
}

\author{
Anna M. Wobus ${ }^{a}$ Eckhard Wolf ${ }^{b}$ Henning M. Beier ${ }^{c}$ \\ aln vitro Differentiation Group, Institute of Plant Genetics, IPK Gatersleben; b Department of Molecular Animal \\ Breeding and Genetics, Gene Center, Ludwig Maximilian University, Munich; 'Institute of Anatomy and \\ Reproductive Biology, RWTH of Aachen, Germany
}

Technological advances of the last 2 years in mammalian nuclear transfer techniques [Wilmut et al., 1997] and in the establishment of human embryonic stem cell lines [Shamblott et al., 1998; Thomson et al., 1998] formed the background of the International Workshop on 'Embryonic Stem Cells and Nuclear Transfer Strategies' organized at the Gene Center, Munich, September 1999. The aim of the meeting was to bring together scientists working in the stem cell field and those working on somatic nuclear transfer techniques to discuss the present state and prospects of both technologies for basic and applied research and future use in medicine and livestock breeding. 'Biology of embryonic stem cells', 'Nuclear transfer strategies' and 'Stem cell differentiation - Cell therapy' covered the main topics of the meeting.

It became clear that we are far away from understanding the processes involved in stem cell self-renewal and differentiation as well as the mechanisms resulting in reprogramming of nuclei from somatic cells after transfer into enucleated oocytes. However, data were presented which showed the enormous potential of the embryonic stem cell technology for tissue transplantation in the

Report of an International Workshop at the Gene Center of Munich, Germany, September 9-10, 1999. future. About 150 participants from Germany, European countries, and from the United States participated in the meeting.

In his opening lecture 'The oocyte - the ultimate stem cell' Jonathan Van Blerkom (University of Colorado, USA) demonstrated and discussed the oocyte contributions to embryonic development. Unique protein domains, concentration gradients, asymmetric protein distributions and polarities are principal forces establishing the identity and fate of individual blastomeres or cells

\section{Abbreviations used in this paper}

EG embryonic germ

ERK extracellular signal-regulated kinase

ES embryonic stem

gp glycoprotein

ICM inner cell mass

JAK Janus kinase

LIFR leukemia inhibitory factor receptor

MAPK mitogen-activated protein kinase

MEK MAP/ERK kinase

MPF mitosis-promoting factor

PG primordial germ

STAT signal transducer and activator of transcription

\begin{tabular}{ll}
\hline KARGER & ( ) 2000 S. Karger AG, Basel \\
Fax +4161306 1234 $34-6405 / 00 / 1661-0001 \$ 17.50 / 0$ \\
$\begin{array}{l}\text { E-Mail karger@karger.ch } \\
\text { www.karger.com }\end{array}$ & $\begin{array}{l}\text { Accessible online at: } \\
\text { www.karger.com/journals/cto }\end{array}$
\end{tabular}

PD Dr. Anna M. Wobus

In vitro Differentiation Group

IPK Gatersleben, Corrensstrasse 3

D-06466 Gatersleben (Germany)

Tel. +49 39482 5256, Fax +49 39482 5481/5500, E-Mail wobusam@ipk-gatersleben.de 
during early development in most of the investigated species. Van Blerkom and his coworkers [Antczak and Van Blerkom, 1997, 1999] showed that these same principles exist during mammalian and human early development in the form of at least two representative regulatory proteins, leptin and STAT3. Analysis of leptin and STAT3 in intact ovarian follicles before ovulation suggested that these proteins are maternally derived and, in particular, that a subpopulation of epithelial follicle cells could be partly responsible for the establishment of their polarized distribution in the oocyte. Detailed investigation of the vascularization and perfusion of individual ovarian follicles revealed a significant difference in these vital alimentations from one follicle to another. Follow-up of the developmental capacity of individual oocytes after follicle puncture and in vitro fertilization demonstrated a highly positive correlation between poorly nourished follicles and defective early embryonic development [Van Blerkom, 1998]. Further parameters of polarized cytoplasmic organization of the oocyte were demonstrated by the local concentration of mitochondria around the two pronuclei forming a 'doughnut-like' ring around these two characteristically arranged and allocated nuclei of the fertilized oocyte. Allocation of mitochondria may be of significance still in blastomeres, because mitochondria-free blastomeres undergo fragmentation. These fascinating results of oocyte and cleavage stage cytoplasmic organization were discussed with respect to the proposition that polarized location of proteins and cytoplasmic organelles may have critical roles in early embryonic development and may be also involved in the determination of the animal pole of the oocyte as well as in the establishment of the inner cell mass and trophoblast in the mammalian preimplantation stage embryo.

In the first session 'Biology of embryonic stem cells', Austin Smith (Centre for Genome Research, Edinburgh, UK) presented an overview on the control of stem cell proliferation and differentiation. Self-renewal of undifferentiated mouse ES cells is regulated by a LIFR/gp130 signaling complex. LIF binds to LIFR and gp130, thereby activating the receptor-associated JAK kinases. Subsequent JAK activation and phosphorylation of receptor tyrosines leads to stimulation of both the STAT and MAPK signaling pathways [Niwa et al., 1998]. There were several lines of evidence that ERK activation is involved in early embryonic differentiation. However, pretreatment of ES cells with PD098059, an inhibitor of ERKmediating MEK enzymes, did not impair ES cell selfrenewal. Several possibilities by which STAT3 activity may block ES cell differentiation have been discussed: (i) activation of genes maintaining pluripotency (i.e. Oct-4); (ii) influence on cell cycle progression; (iii) regulation of genes involved in growth control, or (iv) blocking the activity of signals that direct differentiation. At present, a mechanism of stem cell regulation is discussed which involves a coordinated balance between STAT versus ERK signaling pathways to regulate self-renewal and differentiation: STAT3 may act by repressing transcription of differentiation genes, whereas ERK-dependent factors may induce their expression [Burdon et al., 1999].

Oct-4, a transcription factor of the POU family is another important factor maintaining totipotency or pluripotency, respectively, of embryonic cells at early developmental stages (i.e. zygotes, blastomeres, ICM, embryonic ectoderm, primordial germ cells) [Pesce et al., 1999]. Hans Schöler (EMBL, Heidelberg; now University of Pennsylvania, Philadelphia, Pa., USA) summarized the present knowledge of the molecular and cellular functions of Oct-4. It is suggested that not only leptin/STAT3 proteins are located in a highly polarized, asymmetric distribution, but also Oct- 4 might be regulated in a positiondependent manner in the early embryo. The finding that Oct-4-deficient embryos died shortly after implantation due to a lack of ICM development demonstrated that Oct4 plays an important role in the development of early embryos. Oct-4 loss of function caused embryonic cells to exit the totipotent cycle when the first lineage decision occurred in the embryo. The analysis of transgenic mice in which LacZ reporter genes were expressed under the control of different parts of the Oct-4 regulatory region provided evidence for two distinct enhancers located upstream of the promoter. Further work has to show how these enhancers and cis-acting elements within the enhancers (or other regions of the gene) regulate the expression of Oct- 4 in totipotent cells. The germ-line competence and Oct-4 expression in primordial germ (PG) cells is another aspect. In this context it is suggested that the extraembryonic localization of PG cells may protect them from Oct-4 downregulation, in a way that the positional information may be involved in the regulation of gene function via inductive signals. It was found that a 'switch' in the activity from the Oct-4 proximal enhancer to the distal enhancer temporally and spatially coincided with the location of PG cells suggesting that the 'reprogramming' of Oct-4 expression in PG cells may be under the control of the same signal. In this view, the segregation of Oct- 4 expressing cells in the extra-embryonic mesoderm of mouse embryos would mean that germ-line competent cells escape from differentiation-inducing signals and maintain a totipotent (or pluripotent) phenotype. 
Another important problem discussed at the meeting was the developmental potential of blastocyst-derived ES versus PG cell-derived EG cells introduced by Azim Surani (Wellcome, CRC Institute, Cambridge, UK) in his lecture on 'Nuclear reprogramming and imprinting in the germ line'.

Functional differences exist between parental genomes during mouse development because of the differential expression of imprinted genes. In addition, differences in allele-specific methylation and $\mathrm{X}$-chromosome inactivation distinguish the germ cell lineage from somatic cells [Surani, 1999]. Germ cells are essentially devoid of gametic imprints. To test how the imprint-free PG cell nucleus affects development, nuclei from male PG cells from day E14.5 to day E16.5 of the fetal gonad were transplanted into enucleated oocytes. The reconstructed embryos developed until day 9.5 of gestation, but displayed reduced size and abnormalities of the placenta suggesting that gametic imprints are essential for normal development [Kato et al., 1999]. These findings point to an important factor in the discussion on the use of preimplantation embryos versus fetal PG cells for the isolation of human pluripotent cells, providing the basis for cell therapy. Given the fact that many genes (about 40 identified genes) are paternally or maternally imprinted and are important for cellular function and behavior [ $\mathrm{Li}$ et al., 1999], it may be difficult to use PG cells from fetuses equivalent to ES cells from embryos [Steghaus-Kovacs, 1999]. In this respect, the stage of development at which the PG cells are isolated and cultivated as embryonic germ cell lines seems to be critical.

The second part of the meeting, "Nuclear transfer strategies', was covered by Keith Campbell (PPL Therapeutics, Roslin, UK) and Jose B. Cibelli (Advanced Cell Technology, Worcester, Mass., USA). Keith Campbell gave an overview over the technical considerations that had to be taken to finally succeed in producing live lambs from cultured cells by nuclear transfer [Campbell et al., 1996b]. Nuclear transfer requires a suitable constellation between stage of cell cycle of donor cell and recipient cytoplasm resulting in successful re-programming of gene expression and correct ploidy of the reconstructed embryo. When oocytes with high MPF activity are used as recipients, normal diploid embryos result only after transfer of nuclei in G1. When using nuclei in the S phase, the chromatin is pulverized during premature chromatin condensation, whereas G2 nuclei give rise to tetraploid embryos. In combination with preactivated oocytes which are characterized by low MPF activity, nuclei from all stages of the cell cycle can support the development of normoploid embryos [Campbell et al., 1996a]. The molecular mechanisms underlying nuclear reprogramming are only partially known. The process involves a switch-off of transcription, modifications of the chromatin and again a start of transcription. Nuclei late in G2, in M, in early G2 or in G0 seem to be more amenable to reprogramming than nuclei in other stages of the cell cycle. This may be due to a number of features, such as chromatin condensation, removal of transcription factors etc. Empirical data suggest that every mitotic division before the onset of transcription is positive for successful re-programming of the donor nucleus. The onset of transcription is at the 2cell stage in mouse, the 4-cell stage in pig, the 8-cell stage in sheep and cow, and at a stage of 4,000 cells in the frog. This may explain the high efficiency of nuclear transfer in ruminants as compared to pig and mouse.

The second part of the talk summarized applications of somatic cell nuclear transfer, particularly the cloning of transgenic farm animals from transfected cells which was first demonstrated by the generation of human factor IX transgenic sheep [Schnieke et al., 1997]. The major advantages as compared to classical DNA-microinjection technique are a reduction in costs and animals required. Furthermore, the time to set up a production herd is reduced from 44 to 18 months and from 78 to 33 months in sheep and cow, respectively. Another advantage is the possibility of introducing targeted mutations in cultured cells. At PPL, gene targeting in cultured fetal fibroblasts was successful in $9 \%$ of the selected clones.

Jose B. Cibelli presented a similar cost-efficiency calculation for the DNA-microinjection vs. the nuclear transfer technique of gene transfer. However, he pointed out the high incidence of abnormalities of pregnancies and calves derived from nuclear transfer. The alterations observed include placentomas which are enlarged but reduced in number and hydrallantois, and fatty liver and heart abnormalities in the born offspring. Nevertheless, his group was the first to produce transgenic cattle by nuclear transfer from nonquiescent fetal fibroblasts [Cibelli et al., 1998a]. Fetal fibroblasts have been successfully used for nuclear transfer after up to 30-35 population doublings. In addition, transgenic bovine chimeras were produced by reintroduction into preimplantation embryos of ES-like cells which were derived by nuclear transfer from transfected fetal fibroblasts [Cibelli et al., 1998b]. The feasibility of using cells from transgenic cloned bovine fetuses for therapy has been demonstrated by improved performance of a rat model of Parkinson's disease following transplantation of these cells into immunosuppressed animals [Zawada et al., 1998]. However, for cell 
therapy, selection of a pure population of a specific cell type is essential. This can be achieved, in principle, by transfecting cells with a selectable marker gene that is active only in the desired cell type.

The third topic of the meeting was devoted to 'Stem cell differentiation - Cell therapy'. The capacity of ES cells to differentiate under appropriate conditions into a broad spectrum of cell types and to generate multiple lineages in culture may be used in the future for human tissue repair. In this context, no single cell or universal donor is likely to be useful as cellular graft for all diseases. Different sources, i.e. ES cells vs. stem cells from the bone marrow or fetal brain are potential cell types to be used in somatic cell therapy.

As first speaker of the session, Oliver Brüstle (University of Bonn, Germany) reported on 'Transplantation of embryonic stem cell-derived neuronal precursors'. He used mouse ES cells to differentiate them into precursors for oligodendrocytes and astrocytes. Glial precursor cells were transplanted into the spinal cord of myelin-deficient rats, an animal model for the hereditary human myelin disorder Pelizaeus-Merzbacher disease. ES cell-derived precursors integrated, interacted with host neurons, and efficiently myelinated axons in brain and spinal cord [Brüstle et al., 1999]. Together with earlier reports on using ES cell-derived cardiac cells (selected by a myosin heavy chain promoter-neomycin phosphotransferase construct) [Klug et al., 1996], these data showed that ES cells indeed have the potential to serve as a valuable source of cell type-specific somatic precursor (i.e. neuronal) or differentiated (i.e. cardiac) cells for tissue repair.

The characterization of pluripotent hematopoietic progenitor cells of different sources for transplantation and gene therapy was the main topic of the lecture given by Anthony D. Ho (University of Heidelberg, Germany). CD34+ cells from fetal liver, fetal bone marrow, umbilical cord blood, adult bone marrow, and mobilized peripheral blood were sorted and cultured as single cells. The CD34+/CD38-/HLA-DR+ subset contained the highest number of candidate stem cells among the various immunophenotypes. Fetal liver contained the highest proportion of CD34+ cells (11.4\%) and the highest level of CD34+/CD38-/HLA-DR+ subsets (34.7\%) among cells from various ontogenic ages. Therefore, cells from the fetal liver appeared to represent the best source for ex vivo stem cell expansion and genetic manipulation [Huang et al., 1998].

Another important aspect of stem cell properties with respect to cell transplantation is the asymmetry of cell divisions. Using time lapse and fluorescence imaging it was possible to monitor the divisional history of distinct progenitor cells. Asymmetric divisions were found to occur in pluripotent hematopoietic stem cells. One of the important tasks in the stem cell field is to identify the regulatory molecules responsible for asymmetric divisions generating differentiated and self-renewal stem cell populations.

In his closing lecture, Axel Haverich (University of Hannover, Germany) summarized the requirements for cell, tissue or organ transplantations. Because of possible endogenous retrovirus contaminations, xenotransplantation is restricted in human transplantation therapy. Therefore, efforts are directed to allogenic and autologous tissue grafts [Gage, 1998]. Allogenic transplantation by using ES cell-derived cells would require the genetic manipulation of histocompatibility [Rathjen et al., 1998]. Autologous transplantation would, in principle, require the nuclear transfer of 'individual' human somatic cells into enucleated oocytes, further development into blastocysts, ES cell generation and differentiation into somatic cells [Cibelli et al., 1998b; Prelle et al., 1999]. These 'individualized' somatic cells would create the principal source for autologous tissue grafts using ES cells [Wilmut, 1998; Boheler and Fiszman, 1999; Solter, 1999]. However, up to now, the state of knowledge and the ethical and social implications do not justify experiments using human embryos [Shapiro, 1999]. Before any use of the cloning technology for human cell therapy will be possible, further research including animal models and stem cell differentiation approaches in culture (i.e. identification of differentiation factors, selective differentiation strategies, reporter gene assays) is necessary to understand the basic principles of pluripotent stem cell differentiation and the mechanisms involved in reprogramming somatic cell nuclei. 


\section{References}

Antczak, M., J. Van Blerkom (1997) Oocyte influences on early development: The regulatory proteins leptin and STAT3 are polarized in mouse and human oocytes and differentially distributed within the cells of the preimplantation stage embryo. Mol Hum Reprod 3: 10671086.

Antczak, M., J. Van Blerkom (1999) Temporal and spatial aspects of fragmentation in early human embryos: Possible effects on developmental competence and association with the differential elimination of regulatory proteins from polarized domains. Hum Reprod 14: 429-447.

Boheler, K.R., M.Y. Fiszman (1999) Can exogenous stem cells be used in transplantation? Cells Tissues Organs 165: 237-245.

Brüstle, O., N.K. Jones, R.D. Learish, K. Karram, K. Choudhary, O.D. Wiestler, I.D. Duncan, R.D.G. McKay (1999) Embryonic stem cellderived glial precursors: A source of myelinating transplants. Science 285: 54-65.

Burdon, T., I. Chambers, C. Stracey, H. Niwa, A. Smith (1999) Molecular mechanisms regulating self-renewal and differentiation of pluripotent embryonic stem cells. Cells Tissues Organs 165: 131-143.

Campbell K.H., P. Loi, P.J. Otaegui, I. Wilmut (1996a) Cell cycle co-ordination in embryo cloning by nuclear transfer. Rev Reprod 1: 4046.

Campbell, K.H.S., J. McWhir, W.A. Ritchie, I. Wilmut (1996b) Sheep cloned by nuclear transfer from a cultured cell line. Nature 380: 6466.

Cibelli, J.B., S.L. Stice, P.G. Golueke, J.J. Kane, J. Jerry, E.S.C. Blackwell, F.A. Ponce de Leon, J.M. Robl (1998a) Cloned transgenic calves produced from nonquiescent fetal fibroblasts. Science 280: 1256-1258.
Cibelli, J.B., S.L. Stice, P.G. Golueke, J.J. Kane, J. Jerry, E.S.C. Blackwell, F.A. Ponce de Leon, J.M. Robl (1998b) Transgenic bovine chimeric offspring produced from somatic cell-derived stem-like cells. Nat Biotechnol 16: 642-646.

Gage, F.H. (1998) Cell therapy. Nature 392: 18 24.

Huang, S., P. Law, D. Young, A.D. Ho (1998) Candidate hematopoietic stem cells from fetal tissues, umbilical cord blood vs. adult bone marrow and mobilized peripheral blood. Exp Hematol 26: 1162-1171.

Kato Y., W.M. Rideout 3rd, K. Hilton, S.C. Barton, Y. Tsunoda, M.A. Surani (1999) Developmental potentials of mouse primordial germ cells. Development 126: 1823-1832.

Klug, M., M.J. Soonpa, G.Y. Koh, L.J. Field (1996) Genetically selected cardiomyocytes from differentiating embryonic stem cells form stable intracardiac grafts. J Clin Invest 98: 216-224.

Li, L., E.B. Keverne, S.A. Aparicio, F. Ishino, S.C. Barton, M.A. Surani (1999) Regulation of maternal behavior and offspring growth by paternally expressed Peg3. Science 284: 330-333.

Niwa, H., T. Burdon, I. Chambers, A. Smith (1998) Self-renewal of pluripotent embryonic stem cells is mediated via activation of STAT3. Genes Dev 12: 2048-2060.

Pesce, M., K. Anastassiadis, H.R. Schöler (1999) Oct-4: Lessons of totipotency from embryonic stem cells. Cells Tissues Organs 165: 144-152.

Prelle, K., I.M. Vasiliev, S.G. Vasilieva, E. Wolf, A.M. Wobus (1999) Establishment of pluripotent cell lines from vertebrate species: Present status and future prospects. Cells Tissues Organs 165: 220-236.

Rathjen, P.D., J. Lake, L.M. Whyatt, M.D. Bettess, J. Rathjen (1998) Properties and uses of embryonic stem cells: Prospects for application to human biology and gene therapy. Reprod Fertil Dev 10: 31-47.

Schnieke, A.E., A.J. Kind, W.R. Ritchie, K. Mycock, A.R. Scott, M. Ritchie, I. Wilmut, A. Colman, K.S. Campbell (1997) Human factor IX transgenic sheep produced by transfer of nuclei from transfected fetal fibroblasts. Science 278: 2130-2133.
Shamblott, M.J., J. Axelman, S. Wang, E.M. Bugg, J.W. Littlefield, P.J. Donovan, P.D. Blumenthal, G.R. Huggins, J.D. Gearhart (1998) Derivation of pluripotent stem cells from cultured human primordial germ cells. Proc Natl Acad Sci USA 95: 13726-13731.

Shapiro, H.T. (1999) Ethical dilemmas and stem cell research. Science 285: 265.

Solter D (1999) Cloning and embryonic stem cells: A new era in human biology and medicine. Croat Med J 40: 309-318.

Steghaus-Kovacs (1999) Ethical loophole closing up for stem cell researchers. Science 286: 31 .

Surani, M.A. (1999) Reprogramming a somatic nucleus by trans-modification activity in germ cells. Semin Cell Dev Biol 10: 273-277.

Thomson, J.A., J. Itskovits-Eldor, S.S. Shapiro, M.A. Waknitz, J.J. Swiergiel, V.S. Marshall, J.M. Jones (1998) Embryonic stem cell lines derived from human blastocysts. Science 282: 1145-1147.

Van Blerkom, J. (1998) Epigenetic influences on oocyte developmental competence: Perifollicular vascularity and intrafollicular oxygen. J Assist Reprod Genet 15: 226-234.

Wilmut, I., A.E. Schnieke, J. McWhir, A.J. Kind, K.H.S. Campbell (1997) Viable offspring derived from fetal and adult mammalian cells. Nature 385: 810-813.

Zawada, W.M., J.B. Cibelli, P.K. Choi, E.D. Clarksen, P.J. Golueke, S.E. Witta, K.P. Bell, J. Kane, F.A. Ponce de Leon, D.J. Jerry, J.M. Robl, C.R. Freed, S.L. Stice (1998) Somatic cell cloned transgenic bovine neurons for transplantation in parkinsonian rats. Nat Med 4: 569-574. 